\title{
Contact Modeling and Performance Evaluation of a Radial Standing Wave Ultrasonic Motor
}

\author{
Chunrong Jiang $\mathbb{D}$, ${ }^{1}$ Xiaoxiao Dong, ${ }^{2}$ Long Jin $\mathbb{D}^{1},{ }^{2}$ and Danhong Lu $\mathbb{D}^{1}$ \\ ${ }^{1}$ School of Electric Power Engineering, Nanjing Institute of Technology, Nanjing 211167, China \\ ${ }^{2}$ School of Electrical Engineering, Southeast University, Nanjing 210096, China \\ Correspondence should be addressed to Chunrong Jiang; jiangcr@njit.edu.cn
}

Received 27 February 2019; Accepted 22 April 2019; Published 19 May 2019

Academic Editor: Michele Brun

Copyright (c) 2019 Chunrong Jiang et al. This is an open access article distributed under the Creative Commons Attribution License, which permits unrestricted use, distribution, and reproduction in any medium, provided the original work is properly cited.

\begin{abstract}
The focus of this paper is to propose a contact model of a radial standing wave ultrasonic motor in order to evaluate the motor performance accurately. The contact behavior between the stator and rotor is characterized by test and a continuous contact on the contact interface is confirmed. A contact model describing the continuous contact is then developed with analytical method. The stator vibration, the force transmission between the stator and rotor, and the output of the motor are analyzed. The impacts of different vibration amplitudes and structural parameters on the performances of the motor are evaluated based on the proposed model. Finally, a test platform for measuring the performance of the motor is built and torque-speed curves of the motor under different voltages are measured. The accuracy of the contact model is verified by comparison between measurement and calculation results. The proposed model not only can be used for design and optimization of the radial standing wave ultrasonic motor but also offers insight into the contact mechanics of standing wave ultrasonic motors.
\end{abstract}

\section{Introduction}

Ultrasonic motors use a friction drive that transfers mechanical vibration of the stator into the motion of the rotor. They have many advantages such as quick response, high torque at low speed without gear, high energy density, and selflock when power is off $[1,2]$. The mechanical performances of ultrasonic motors are strongly dependent on contact mechanics. Therefore, studies on contact models of ultrasonic motors are of significant importance in order to predict and evaluate the motor performance accurately.

There are two main different types of ultrasonic motors, the traveling wave type and the standing wave type. The contact mechanics of traveling wave ultrasonic motors and standing wave ultrasonic motors are different. In traveling wave ultrasonic motors, the stator and rotor are in continuous contact state and the contact area between the stator and rotor moves along with the wave crest of the stator. On the contrary, in standing wave ultrasonic motors, the stator and rotor are in intermittent contact state and the contact area occurs at the same and small area of the stator [3]. Lots of previous works [4-13] have been published on modeling of contact mechanics of traveling wave ultrasonic motors. However, only a few works are devoted to the study of contact models of standing wave ultrasonic motors. Moal et al. [14] investigated the mechanical energy transductions in a standing wave ultrasonic motor based on an analytical model in which the intermittent stator/frame contact was characterized. Twiefel et al. [15] conducted an experimental investigation on the measurement of the contact tip trajectory of a standing wave ultrasonic motor and pointed out that the trajectory was affected by contact behavior, which resulted in deformation of the elliptical motion. Shi et al. [16, 17] proposed a contact model for describing the contact mechanics of a standing wave linear ultrasonic motor without considering the deformation of elliptical trajectory of the driving tip. Li et al. $[18,19]$ studied the contact mechanics of a bimodal standing wave ultrasonic motor based on an analytical model in which the stick and slip dynamics were characterized. Despite existing researches, the contact mechanics of standing wave ultrasonic motors are less understood compared with traveling wave ultrasonic motors. The motion trajectory of driving tips in 


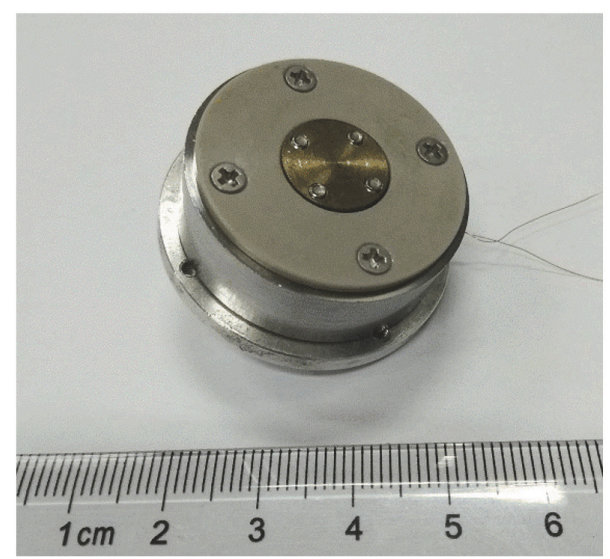

FIGURE 1: Radial standing wave ultrasonic motor.

standing wave ultrasonic motors could be either elliptical or rectilinear. Contact mechanics in different standing wave ultrasonic motors may vary from each other due to different driving tip trajectories and the variety of the piezoelectric actuators used for standing wave ultrasonic motors. A widely applied contact model of standing wave ultrasonic motors has not been found up to now. In order to predict and evaluate the motor performance more accurately, different contact models need to be developed for different standing wave ultrasonic motors according to their specific contact mechanics.

A radial standing wave ultrasonic motor was reported in [20], in which the contact mechanics of the motor were not discussed. The primary goal of this paper is to propose a contact model for the radial standing wave ultrasonic motor in order to evaluate the motor performance accurately. The contact behavior between the stator and rotor is characterized by test. An analytical contact model is then proposed, which reveals the force transmission between the stator and rotor. The performances of the motor under different parameters are evaluated based on the contact model. The comparison between measurement and calculation results is conducted to validate the accuracy of the proposed model. The proposed model not only can be used for design and optimization of the radial standing wave ultrasonic motor but also offers insight into the contact mechanics of standing wave ultrasonic motors.

\section{Configuration and Operating Principle}

The radial standing wave ultrasonic motor studied in this paper is shown in Figure 1, and its configuration is shown in Figure 2. The piezoelectric ceramic (PZT) is polarized in its axial direction and bonded to the metal ring with adhesive. Several leaf springs are soldered to the circumference of the metal ring as driving feet. The stator of the motor is comprised of the PZT, the metal ring, and the leaf springs. The motor adopts the first-order radial vibration mode of the stator as its working mode. By applying a specific high frequency voltage to the top and bottom surface of the PZT, an ultrasonic radial standing wave is excited causing the expansion and shrinking of the metal ring in radial direction,

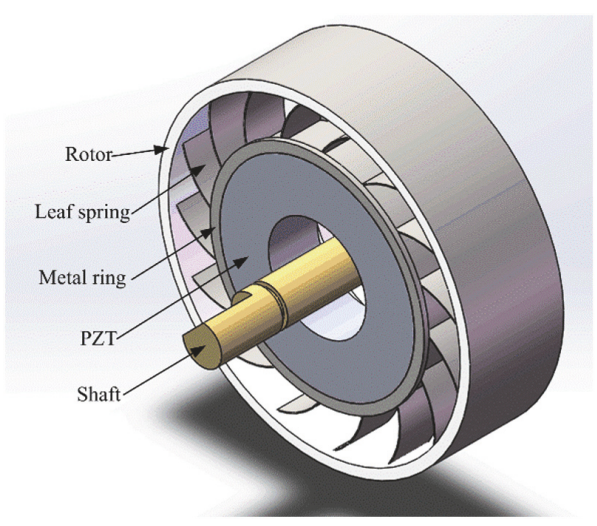

FIgURE 2: Configuration of the radial standing wave ultrasonic motor.

which stimulates movement of the leaf springs along the radial direction. The leaf springs are held pressed against the rotor and keep a certain elastic deformation. They convert the radial vibration into the movement of the contact tips along the tangential direction of the rotor. The contact tips move forward and backward repetitively and cause rotation of the rotor via friction forces at the contact areas. The shaft is connected with the rotor and thus is driven by the rotor.

\section{Contact Behavior Test}

A specific experimental setup presented in Figure 3 was developed aiming at characterizing the contact behavior between the stator and rotor. The stator was removed from the rotor and placed between the upper and lower fixing plates. Two elastic insulating spacers were inserted between the fixing plates and the stator. Preload forces were applied to the surfaces of the two fixing plates so as to keep the stator clamped, which was in accordance with the actual working status of the stator. A printed circuit board that functioned as the rotor was pressed against sidewalls of the two fixing plates causing elastic deformation of the leaf spring. The width of the fixing plates was the same as the inner diameter of the rotor so as to ensure that the deformation of the leaf spring was in consistency with the normal working status. The printed circuit board and the fixing plates were insulated from each other. There were two conductive areas, that was, conductive area $\mathrm{A} 1$ and conductive area $\mathrm{A} 2$, on the printed circuit board, while an insulative area was arranged in the middle to separate the two conductive areas. The leaf spring was in contact with the insulative area and connected the two conductive areas. The conductive area A2 was grounded, whereas the conductive area Al was connected with a DC voltage source through a resistor and its voltage level was recorded on the oscilloscope.

The normal driving frequency of the stator is $74 \mathrm{kHz}$. By applying a voltage whose frequency is around the normal driving frequency to the PZT, the ultrasonic radial vibration of the stator is excited, which stimulates movement of leaf springs. When the leaf spring remains in contact with the printed circuit board, the conductive area A1 is grounded through conductive area A2 due to electrical conductivity 


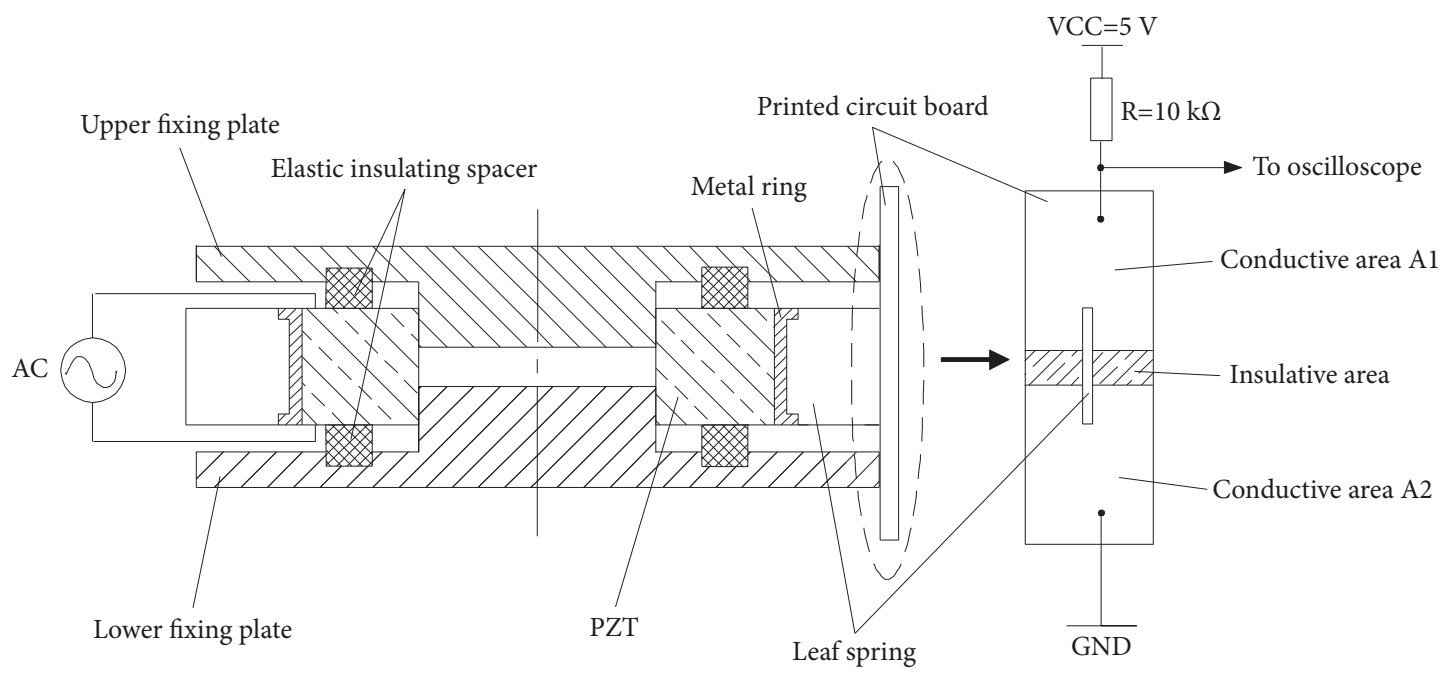

FIGURE 3: Experimental setup for testing contact behavior at the contact interface.

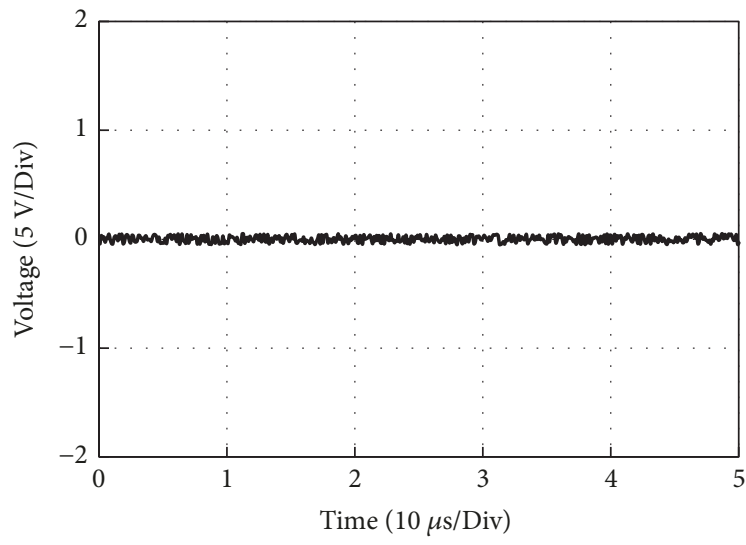

FIGURE 4: Waveform of the contact behavior tests.

of the leaf spring. Therefore, the voltage captured by the oscilloscope is at a logic low level. On the contrary, if the leaf spring separates from the printed circuit board, the conductive area $\mathrm{A} 1$ is then disconnected from ground, and a logic high level voltage is captured. The contact behavior is characterized by the waveform recorded on the oscilloscope. Square waveform recorded on the oscilloscope indicates intermittent contact between the leaf spring and the rotor, whereas a continuous logic low signal indicates continuous contact between them. During the tests, a continuous logic low signal, as shown in Figure 4, is observed even if voltages of different frequencies and amplitudes are applied to the PZT so as to change the vibration amplitude of the stator. The result reveals that the radial standing wave ultrasonic motor possesses continuous contact rather than intermittent contact [14] that occurs in most standing wave ultrasonic motors.

\section{Contact Model}

4.1. Vibration Analysis of the Stator. The motor works at the first-order radial vibration mode and the motion of

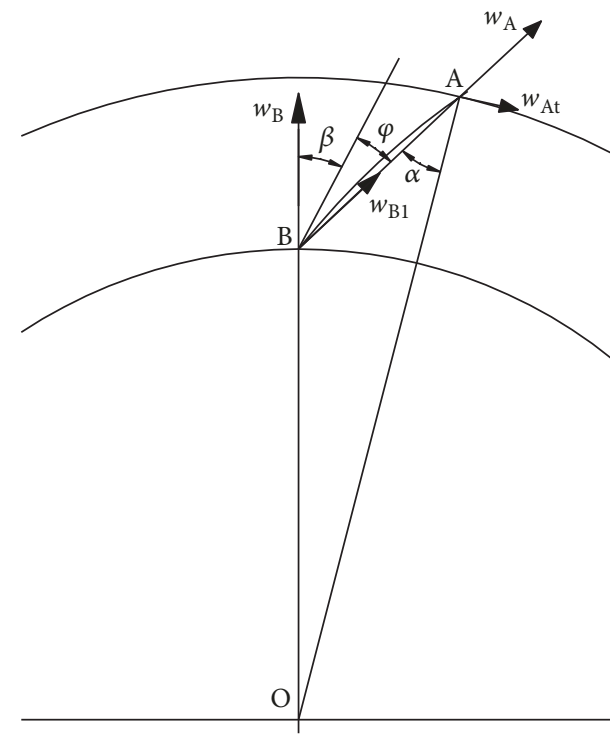

FIGURE 5: Vibration motion of the stator.

the stator is symmetrical. Therefore, only $1 / 16$ of the motor including one leaf spring is considered in the development of the contact model. The vibration motion of the stator is illustrated in Figure 5. The leaf spring is mounted on the metal ring at point $B$ with a mounting angle $\beta$ between the radial direction of point $B$ and direction of the leaf spring before deflection. When the stator is assembled with the rotor, the leaf spring contacts with the rotor at point $A$ and keeps elastic deformation by pressing against the rotor. The deformed leaf spring keeps a shape of arc $A B$. In order to simplify the contact model, the $\operatorname{arc} A B$ is simplified to straight line $\mathrm{AB}$ on account of the small bending deformation of the leaf spring. The angle $\varphi$ is formed due to different positions of the leaf spring during deflection. The angle between line $\mathrm{AB}$ and the radial direction of point 
A is denoted by $\alpha$. The angles $\varphi$ and $\alpha$ can be calculated from

$$
\varphi=\pi-\beta-\cos ^{-1}\left(\frac{r_{1}^{2}+l^{2}-r^{2}}{2 l r_{1}}\right)
$$

and

$$
\alpha=\cos ^{-1}\left(\frac{r^{2}+l^{2}-r_{1}^{2}}{2 l r}\right)
$$

where $r$ and $r_{1}$ are the inner radius of the rotor $(\mathrm{OA}=r)$ and the outer radius of the metal ring $\left(\mathrm{OB}=r_{1}\right)$, respectively, and $l$ is the length of the leaf spring $(\mathrm{AB}=l)$. The stator vibrates at micrometer scale, whereas the structural parameters of the motor are at millimeter scale; hence the variations of $\varphi$ and $\alpha$ caused by the vibration of the stator can be neglected. It means the angles $\varphi$ and $\alpha$ can be considered constant once the structural parameters of the motor are determined.

The radial vibration of point $B$ can be written as

$$
w_{\mathrm{B}}=\Lambda \sin (\omega t)
$$

where $\Lambda$ is the radial vibration amplitude of the stator and $\omega$ is the angular frequency. Decomposing the radial vibration in (3) yields the displacement of point B along line BA as

$$
w_{\mathrm{B} 1}=\Lambda \cos (\beta+\varphi) \sin (\omega t)
$$

The displacement of point $\mathrm{A}$ on the leaf spring is the same as that of point $\mathrm{B}$, that is, $w_{\mathrm{A}}=w_{\mathrm{B} 1}$. Consequently, the displacement of point $A$ along the tangential direction of the rotor can be obtained as

$$
w_{\mathrm{At}}=w_{\mathrm{A}} \sin \alpha=\Lambda \cos (\beta+\varphi) \sin \alpha \sin (\omega t)
$$

By taking derivative of displacement with respect to time, the tangential velocity of point A can be derived as

$$
v_{\mathrm{At}}=\frac{\mathrm{d} w_{\mathrm{At}}}{\mathrm{d} t}=\Lambda \omega \cos (\beta+\varphi) \sin \alpha \cos (\omega t)
$$

The tangential motion of point $\mathrm{A}$ on the leaf spring drives the rotation of the rotor.

4.2. Contact Analysis between the Stator and Rotor. Once the stator is stimulated by a high-frequency voltage, the leaf spring may act on the rotor in two different ways, that is, driving the rotor and blocking the rotor, according to the relative velocity between the rotor and the contact tip on the leaf spring. If the contact tip on the leaf spring moves forward along the same direction as the rotor and meanwhile its speed is higher than the rotor, the leaf spring drives the rotor. On the contrary, if the contact tip on the leaf spring moves forward along the same direction as the rotor whereas its speed is lower than the rotor, or if the contact tip moves backward in the opposite direction of the rotor, the leaf spring blocks the rotor. The force analyses of the two different actions are shown in Figures 6 and 7. When the leaf spring drives the rotor, as shown in Figure 6, the contact point A on the leaf

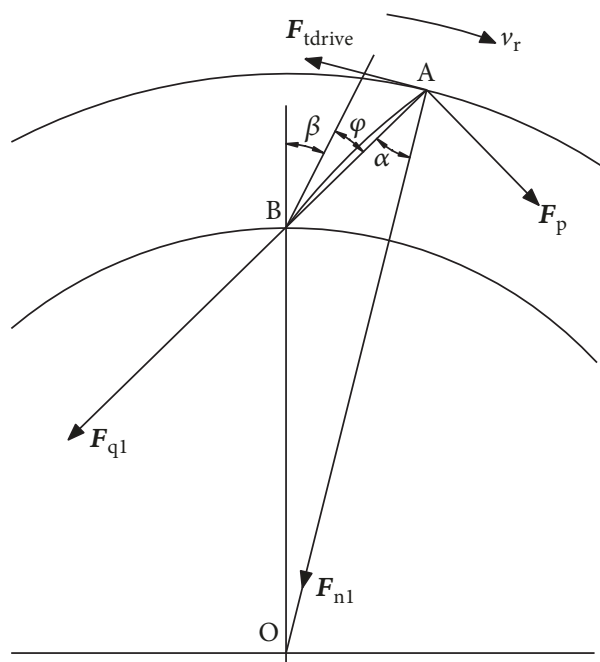

FIGURE 6: Force analysis when the leaf spring drives the rotor.

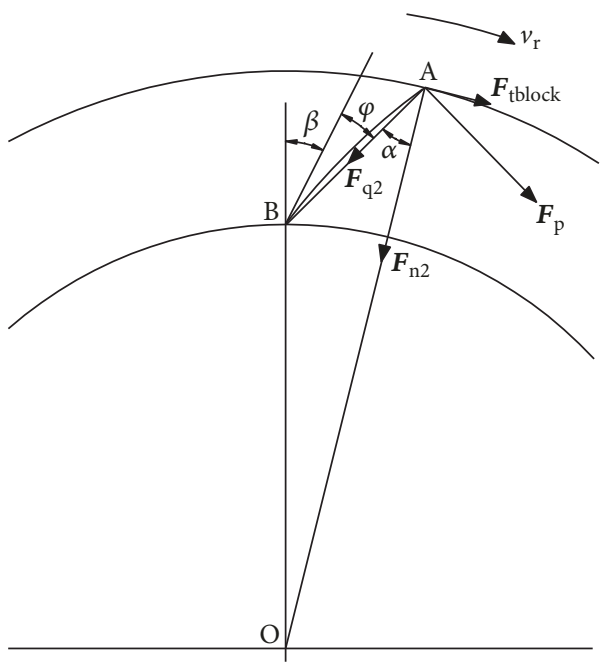

FIGURE 7: Force analysis when the leaf spring blocks the rotor.

spring bears two forces of the rotor, that is, the normal force $F_{\text {n1 }}$ along the radial direction and the friction force $\boldsymbol{F}_{\text {tdrive }}$ along the tangential direction of the rotor. These two forces can be equivalently decomposed into $\boldsymbol{F}_{\mathrm{q} 1}$ and $\boldsymbol{F}_{\mathrm{p}}$, and the relationship between them is given by

$$
\boldsymbol{F}_{\mathrm{q} 1}+\boldsymbol{F}_{\mathrm{p}}=\boldsymbol{F}_{\mathrm{n} 1}+\boldsymbol{F}_{\text {tdrive }}
$$

According to (7), we have

$$
F_{\mathrm{p}}=F_{\mathrm{n} 1} \sin \alpha-F_{\text {tdrive }} \cos \alpha
$$

Let $\mu_{\mathrm{d}}$ be the dynamic friction coefficient between the leaf spring and the rotor; by using Coulomb's Friction Law, we have

$$
F_{\text {tdrive }}=\mu_{\mathrm{d}} F_{\mathrm{n} 1}
$$

Substituting (9) into (8) yields

$$
F_{\text {tdrive }}=\frac{\mu_{\mathrm{d}} F_{\mathrm{p}}}{\sin \alpha-\mu_{\mathrm{d}} \cos \alpha}
$$


When the leaf spring blocks the rotor, as shown in Figure 7 , the direction of friction force $\boldsymbol{F}_{\text {tblock }}$ is opposite to the

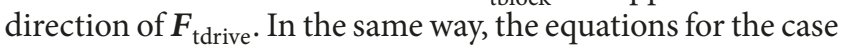
when the leaf spring blocks the rotor can be derived as

$$
\begin{aligned}
\boldsymbol{F}_{\mathrm{q} 2}+\boldsymbol{F}_{\mathrm{p}} & =\boldsymbol{F}_{\mathrm{n} 2}+\boldsymbol{F}_{\text {tblock }} \\
F_{\mathrm{p}} & =F_{\mathrm{n} 2} \sin \alpha+F_{\text {tblock }} \cos \alpha \\
F_{\text {tblock }} & =\mu_{\mathrm{d}} F_{\mathrm{n} 2}
\end{aligned}
$$

and

$$
F_{\text {tblock }}=\frac{\mu_{\mathrm{d}} F_{\mathrm{p}}}{\sin \alpha+\mu_{\mathrm{d}} \cos \alpha}
$$

The stator vibrates at micrometer scale and its effect on the deflection of the leaf spring can be neglected. Hence, the deflection of the leaf spring is considered to be constant regardless of whether the leaf spring drives or blocks the rotor. Consequently, the force $F_{\mathrm{p}}$ causing the deflection can also be considered constant and it is expressed as

$$
F_{\mathrm{p}}=\frac{3 E I \Delta d}{l^{3} \cos \varphi}
$$

where $E$ is Young's modulus of the leaf spring and $I$ is the cross-sectional moment of inertia of the leaf spring. $\Delta d$ is the deflection of the contact tip on the leaf spring and can be estimated from

$$
\Delta d=l \sin \varphi
$$

By substituting (15) into (10) and (14), the driving force and the blocking force of the leaf spring on the rotor can be obtained.

4.3. Output Characteristics of the Motor. The torque and speed of the motor are related to relative motion between the leaf spring and rotor. The relative motion in one vibration cycle is illustrated in Figure 8. The tangential displacement and velocity of contact tip on the leaf spring, that is, $w_{\mathrm{At}}$ and $v_{\mathrm{At}}$, are given by (5) and (6), respectively. $v_{\mathrm{r}}$ denotes the tangential velocity of the rotor. The motion in one vibration cycle $T$ can be distinguished as follows.

From $t=0$ to $t=t_{1}$, the contact tip on the leaf spring moves forward along the same direction as the rotor and its speed is higher than the rotor; hence the movement of the contact tip drives the rotor and the driving force is equal to $F_{\text {tdrive }}$. The tangential speed of the contact tip decreases gradually during this process and reaches the same speed as the rotor at $t_{1}$.

From $t=t_{1}$ to $t=t_{2}\left(t_{2}=T / 4\right)$, the contact tip continues to move forward along the same direction as the rotor, whereas its speed is lower than the rotor. Therefore, the contact tip blocks the rotor and the blocking force is $F_{\text {tblock }}$. The tangential speed of the contact tip continues to decrease during this process and reaches zero at $t_{2}$.

From $t=t_{2}$ to $t=t_{3}\left(t_{3}=3 T / 4\right)$, the contact tip moves backward in the opposite direction of the rotor and consequently blocks the rotor, and the blocking force remains unchanged at $F_{\text {tblock}}$.

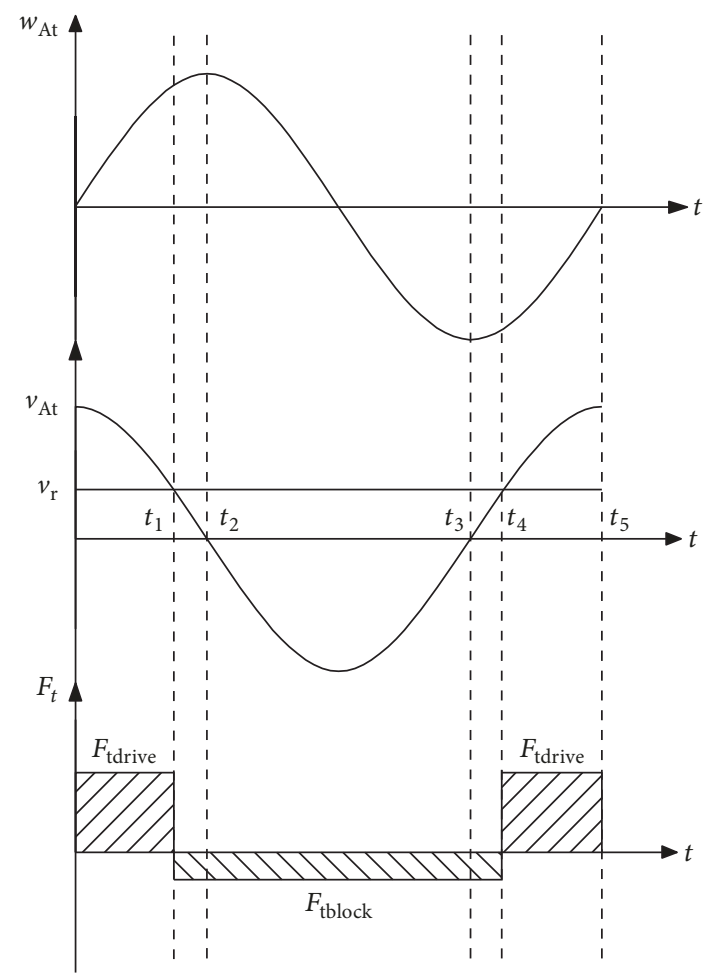

FIGURE 8: Relative motion between the leaf spring and rotor in one vibration cycle.

From $t=t_{3}$ to $t=t_{4}$, the contact tip turns to forward movement again in the same direction as the rotor, whereas its speed is lower than the rotor, so it still blocks the rotor with blocking force $F_{\text {tblock }}$. During this process, the tangential speed of the contact tip increases gradually from zero and reaches the same speed as the rotor at $t_{4}$.

From $t=t_{4}$ to $t=t_{5}\left(t_{5}=T\right)$, the contact tip continuous to move forward in the same direction as the rotor and its speed is higher than the rotor again; thus it drives the rotor with driving force $F_{\text {tdrive }}$. The tangential speed of the contact tip continues to increase during this process.

Asymmetrical contact forces lead to the rotation of the rotor. The average tangential force obtained by the rotor in one cycle is derived as

$$
\begin{aligned}
F_{\text {to }} & =\frac{1}{T}\left(\int_{0}^{t_{1}} F_{\text {tdrive }} \mathrm{d} t-\int_{t_{1}}^{t_{4}} F_{\text {tblock }} \mathrm{d} t+\int_{t_{4}}^{t_{5}} F_{\text {tdrive }} \mathrm{d} t\right) \\
& =\frac{1}{T}\left[2 F_{\text {tdrive }} t_{1}-F_{\text {tblock }}\left(T-2 t_{1}\right)\right]
\end{aligned}
$$

with

$$
t_{1}=\frac{1}{\omega} \cos ^{-1}\left[\frac{v_{r}}{\Lambda \omega \cos (\beta+\varphi) \sin \alpha}\right]
$$

The output torque of the rotor produced by all the leaf springs is given by

$$
T_{\text {out }}=F_{\text {to }} n r=\frac{n r}{T}\left[2 F_{\text {tdrive }} t_{1}-F_{\text {tblock }}\left(T-2 t_{1}\right)\right]
$$


TABLE 1: Parameters of the prototype motor.

\begin{tabular}{lcc}
\hline Parameters & Values \\
\hline Amplitude of drive voltage $\left(V_{\mathrm{p}}\right)$ & 100 \\
Vibration frequency of the stator $f(\mathrm{kHz})$ & 74.0 \\
Radial vibration amplitude of the stator $\Lambda(\mu \mathrm{m})$ & 0.6 \\
Outer radius of the metal ring $r_{1}(\mathrm{~mm})$ & 11 \\
Inner radius of the rotor $r(\mathrm{~mm})$ & 15 \\
Young's modulus of the leaf spring $E\left(\mathrm{~N} / \mathrm{m}^{2}\right)$ & $2.11 \times 10^{11}$ \\
Cross-sectional moment of inertia of the leaf spring $I\left(\mathrm{~m}^{4}\right)$ & $4.17 \times 10^{-16}$ \\
Length of the leaf spring $l(\mathrm{~mm})$ & 5.0 \\
Mounting angle of the leaf spring $\beta\left(^{\circ}\right)$ & 27 \\
Number of the leaf springs $n$ & 16 \\
Dynamic friction coefficient $\mu_{\mathrm{d}}$ & 0.32 \\
\hline
\end{tabular}

where $n$ is the number of leaf springs. The torque-speed curves of the motor can be calculated from (18) and (19).

There are two special cases in the motor rotation, that is, no-load and stalled. When the motor is no-load, the output torque of the rotor calculated from (19) is zero, which yields

$$
t_{1}=\frac{F_{\text {tblock }} T}{2\left(F_{\text {tdrive }}+F_{\text {tblock }}\right)}=\frac{k T}{2(k+1)}
$$

where $k$ is defined as

$$
k=\frac{F_{\text {tblock }}}{F_{\text {tdrive }}}=\frac{\sin \alpha-\mu_{\mathrm{d}} \cos \alpha}{\sin \alpha+\mu_{\mathrm{d}} \cos \alpha}
$$

By substituting $t$ in (6) with $t_{1}$, the no-load speed of the rotor is then derived as

$$
v_{\mathrm{r} 0}=\Lambda \omega \cos (\beta+\varphi) \sin \alpha \cos \left(\frac{k \pi}{k+1}\right)
$$

When the motor is stalled, $v_{\mathrm{r}}$ is equal to zero, which results in $t_{1}$ being equal to $T / 4$. By substituting the value of $t_{1}$ into (19), the stall torque of the rotor is obtained as

$$
T_{\text {stall }}=\frac{n r}{2} F_{\text {tdrive }}(1-k)
$$

\section{Calculations and Experimental Results}

The calculations of motor performances are based on the parameters listed in Table 1. The parameters belong to the motor shown in Figure 1, which has been investigated in the experiments. The resonant frequency of working mode of the motor is $73.3 \mathrm{kHz}$. The applied power frequency is generally slightly higher than the resonant frequency and is set at $74 \mathrm{kHz}$ under normal working condition. The radial vibration amplitude of the stator is measured with laser Doppler vibrometer (PSV-400-M2, Polytec GmbH, Germany). The laser measurement has been carried out on the stator disassembled from the rotor so as to avoid the laser beam being blocked by the rotor.

5.1. Parameter Studies. Based upon the proposed contact model and the parameters, the performances of the motor are calculated by considering varied radial vibration amplitude $\Lambda$, leaf spring length $l$, and mounting angle $\beta$. The results are shown in Figure 9, where the standard parameter configuration corresponding to Table 1 is illustrated by solid lines. It is obvious that the motor has a better performance when the radial vibration amplitude of the stator is increased, as shown in Figure 9(a). The no-load speed of the rotor increases linearly with the vibration amplitude increasing, whereas the stall torque remains constant despite increase of the vibration amplitude. The better performance of the motor at larger vibration amplitude is caused by the rise of driving time on the rotor as the velocity of the leaf spring is proportional to the vibration amplitude. Similarly, the length and mounting angle of the leaf spring also have significant influences on the torque-speed curve of the motor. When the length of the leaf spring increases, the no-load speed and stall torque show a rapid increase at first and then decrease gradually, as shown in Figure 9(b). According to (22), the no-load speed is affected by the angles $\varphi$ and $\alpha$ as well as the value of $k$. The increase of leaf spring length results in increase of the values of $\varphi, \alpha$, and $k$. Under the comprehensive influence of these factors, the no-load speed reaches peak value when the leaf spring length is $4.5 \mathrm{~mm}$. In the same way, according to (23), the stall torque is affected by the values of $k$ and $F_{\text {tdrive }}$. As the leaf spring length increases, the value of $k$ increases, while the driving force $F_{\text {tdrive }}$ increases at first and then decreases, which causes the stall torque to increase at first and then decrease. The stall torque reaches peak value when the leaf spring length is $4.6 \mathrm{~mm}$. Unlike the influence of the leaf spring length, increase of the leaf spring mounting angle leads to decrease of the stall torque, whereas it has no effect on no-load speed, as shown in Figure 9(c). It is helpful to improve the output of the motor by appropriately reducing the length or mounting angle of the leaf spring based upon the parameters noted in Table 1 . However, the leaf spring will bear more stress if the length or mounting angle is reduced, which may result in the break of the leaf spring. Therefore, in order to obtain a reasonable torque-speed output as well as motor life span, the length and mounting angle of the leaf spring in the prototype motor are designed to be $5.0 \mathrm{~mm}$ and $27^{\circ}$, respectively. 

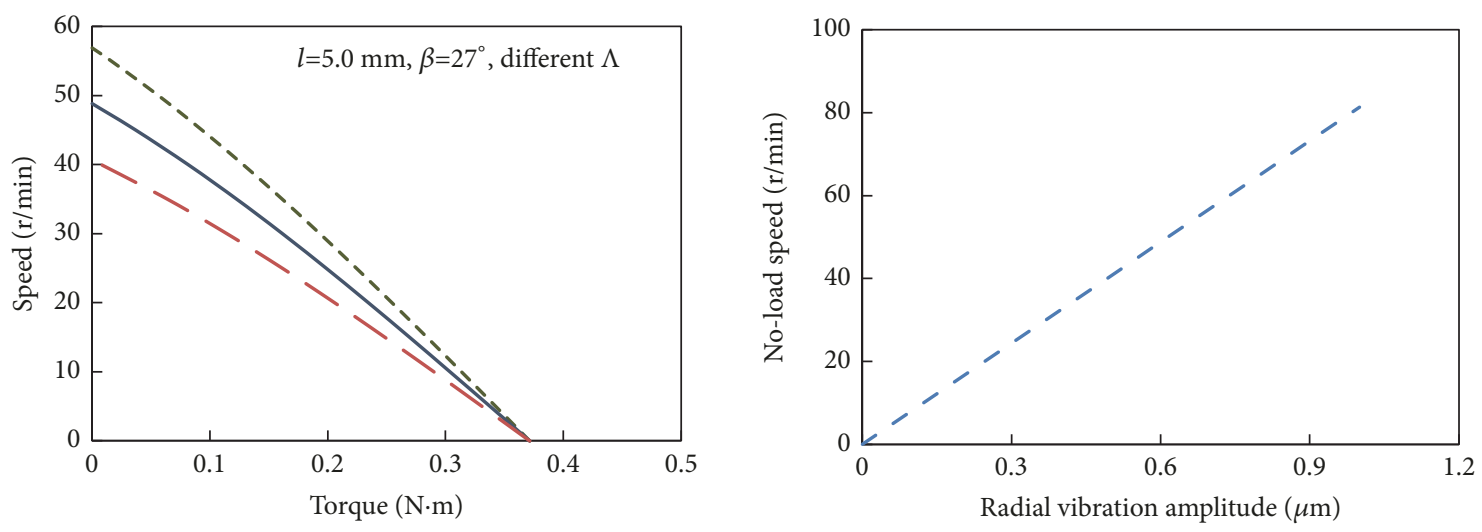

(a)
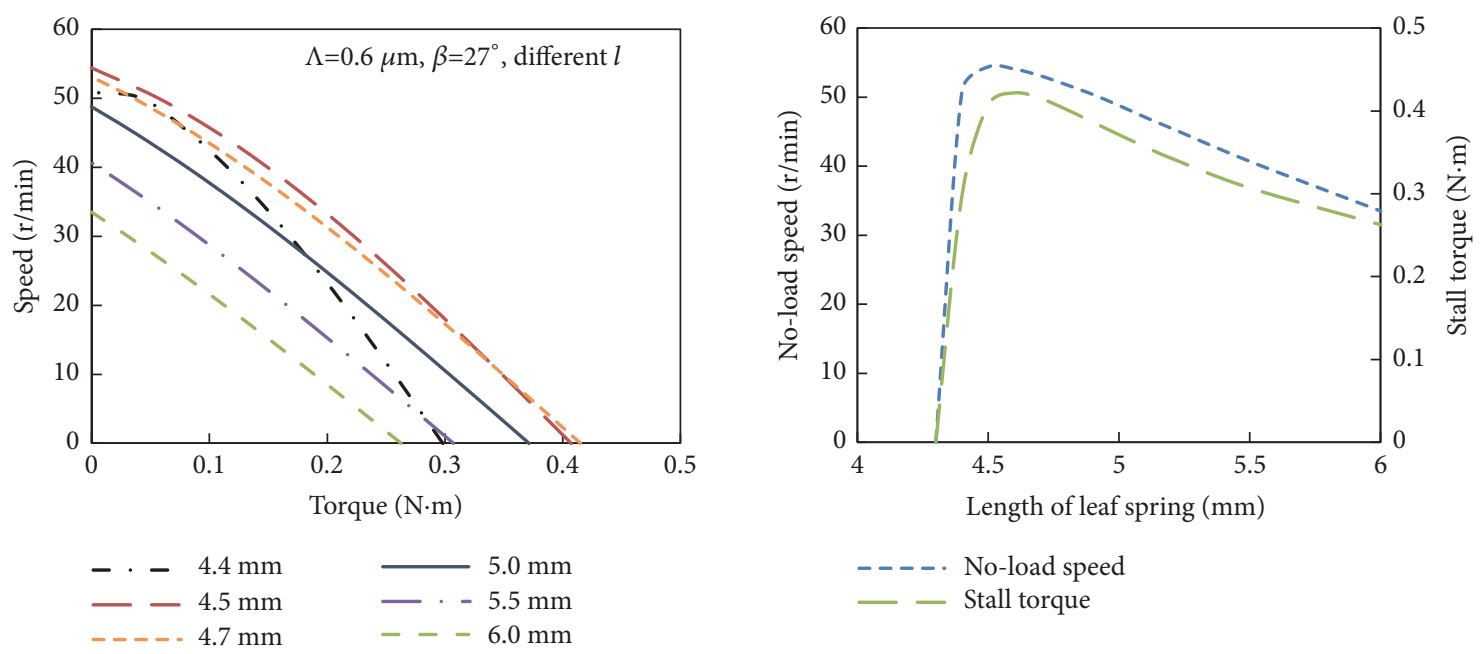

(b)
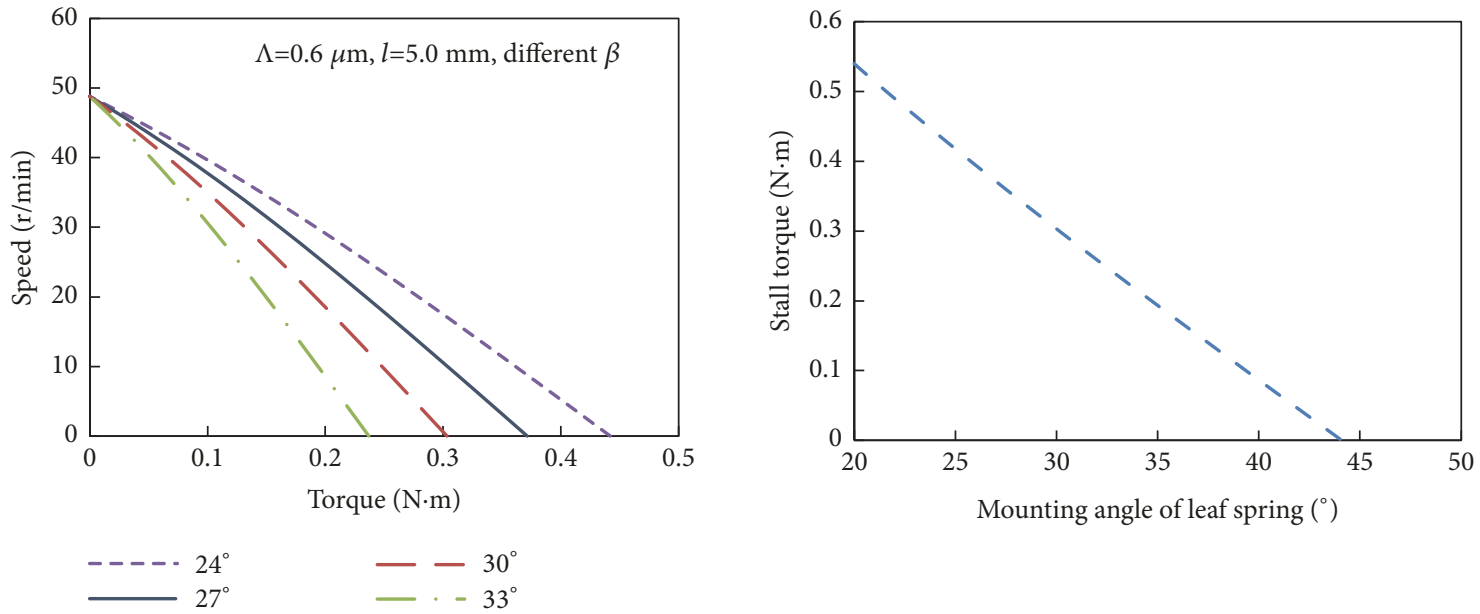

(c)

FIGURE 9: Calculated motor performances under different parameters. (a) Varied radial vibration amplitude of the stator $\left(l=5.0 \mathrm{~mm}, \beta=27^{\circ}\right)$. (b) Varied length of the leaf spring $\left(\Lambda=0.6 \mu \mathrm{m}, \beta=27^{\circ}\right)$. (c) Varied mounting angle of the leaf spring $(\Lambda=0.6 \mu \mathrm{m}, l=5.0 \mathrm{~mm})$. The solid lines represent the same parameters in all diagrams. 
TABLE 2: Radial vibration amplitudes of the stator under different voltages.

\begin{tabular}{lcr}
\hline Voltage amplitude $\left(V_{\mathrm{p}}\right)$ & Driving frequency $(\mathrm{kHz})$ & Radial vibration amplitude $(\mu \mathrm{m})$ \\
\hline 100 & 74.0 & 0.6 \\
90 & 74.0 & 0.5 \\
80 & 74.0 & 0.4 \\
\hline
\end{tabular}

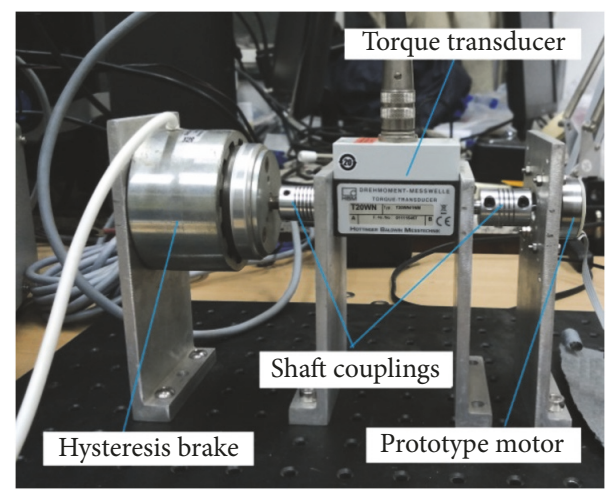

FIGURE 10: Test platform for measuring torque-speed curves.

5.2. Experiments. In order to validate the proposed model, torque-speed measurements were carried out on a test platform, as shown in Figure 10. The hysteresis brake (EBU0.3L, ZF Friedrichshafen AG, Germany) was used as a variable load, which was adjusted by a DC power supply (GPS-4303C, GW Instek, Taiwan). The torque transducer (T20WN, HBM $\mathrm{GmbH}$, Germany) measured both the torque and speed of the ultrasonic motor. The hysteresis brake, torque transducer, and ultrasonic motor were connected by shaft couplings. A sinusoidal wave signal generated by a function generator (WF1974, NF Electronics, Japan) and amplified by a power amplifier (HSA4052, NF Electronics, Japan) was used as the power supply of the motor.

It is not possible to conduct torque-speed measurement and laser measurements simultaneously. Therefore, the laser measurement has been carried out previously to the torque-speed measurement in order to examine the radial vibration amplitude of the stator under different voltages. The measured results are listed in Table 2. Voltages with different amplitudes have been applied individually and the corresponding radial vibration amplitudes of the stator are obtained.

Different voltages listed in Table 2 are applied to the motor individually during torque-speed measurements. The corresponding torque-speed curves are calculated based upon the parameters noted in Tables 1 and 2. Figure 11 shows a comparison between the measured and calculated torquespeed curves, where the measured values are indicated by solid dots. It is shown that the calculated values are basically consistent with the measured ones. The error of the results is caused by the assumption of constant vibration amplitude under the same voltage despite of the variable load. According to [21], the actual vibration amplitude of the stator may be affected by the load torque, which results in the fluctuations in the peaks and troughs of the velocity curve of the stator. The influence of load torque is more significant when the radial vibration amplitude is small, which leads to the larger error in Figure 11(c).

\section{Conclusions}

A contact model for the radial standing wave ultrasonic motor has been developed in this paper. The continuous contact behavior between the stator and rotor is confirmed by contact test results. The stator vibration, the contact force between the stator and rotor, and the rotor output have been analyzed. The influences of different parameters on the performance of the motor have been investigated based upon the proposed model. It is indicated that the radial vibration amplitude of the stator as well as the length and mounting angle of the leaf springs has significant impacts on the performance of the motor. In order to validate the proposed model, the torque-speed curves of the motor under different voltages have been measured and compared with the calculated ones. The results show that the calculated values are basically consistent with the measured values, which verify the validity of the contact model. The proposed model is benefit for design and optimization of the radial standing wave ultrasonic motor.

The changes in resonant frequency and vibration amplitude of the stator due to a variable load are not considered in the proposed model. Further research can be concentrated on the improvement of the model considering the interaction between the load and stator vibration.

\section{Data Availability}

The data used to support the findings of this study are available from the corresponding author upon request.

\section{Conflicts of Interest}

The authors declare that there are no conflicts of interest regarding the publication of this article.

\section{Acknowledgments}

This work is supported by the National Natural Science Foundation of China (no. 51507076 and no. 51777029), the Six Talent Peaks Project of Jiangsu Province (no. KTHY040), and the Open Research Fund of Jiangsu Collaborative 


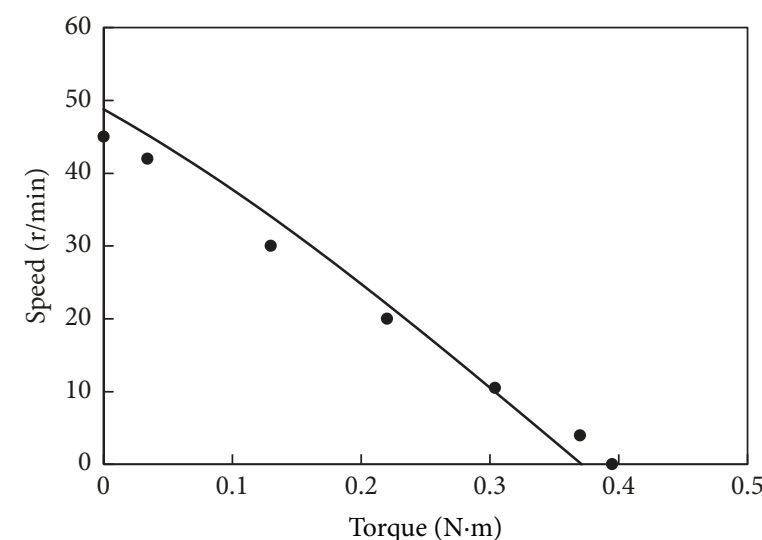

- Measured results Calculated results

(a)

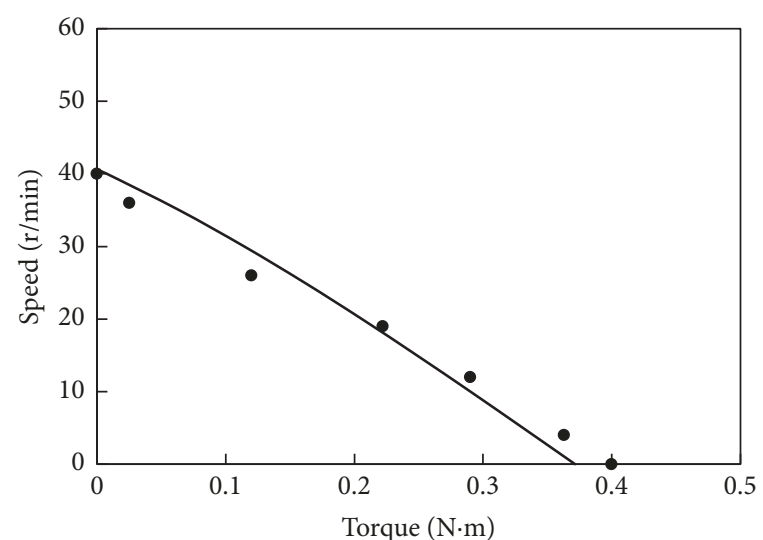

- Measured results Calculated results

(b)

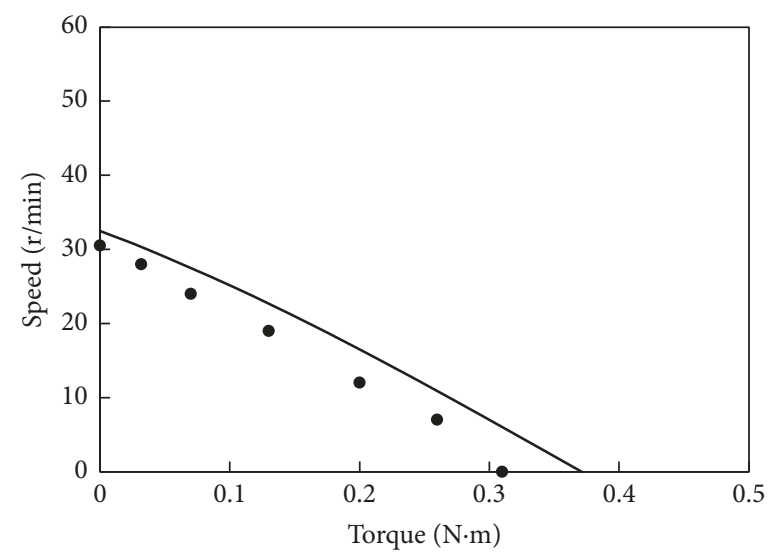

- Measured results Calculated results

(c)

FIGURE 11: Comparison between calculated and measured torque-speed curves. (a) $\Lambda=0.6 \mu \mathrm{m}$. (b) $\Lambda=0.5 \mu \mathrm{m}$. (c) $\Lambda=0.4 \mu \mathrm{m}$.

Innovation Center for Smart Distribution Network (no. XTCX201706).

\section{References}

[1] Y. Liu, J. Yan, L. Wang, and W. Chen, "A two-DOF ultrasonic motor using a longitudinal-bending hybrid sandwich transducer," IEEE Transactions on Industrial Electronics, vol. 66, no. 4, pp. 3041-3050, 2019.

[2] D. Xu, Y. Liu, J. Liu, and W. Chen, "A bonded type ultrasonic motor using the bending of a crossbeam," IEEE Access, vol. 4, pp. 1109-1116, 2016.

[3] J. Wallaschek, "Contact mechanics of piezoelectric ultrasonic motors," Smart Materials and Structures, vol. 7, no. 3, pp. 369381, 1998.

[4] I. A. R. Marquez and V. Bolborici, "A dynamic model of the piezoelectric traveling wave rotary ultrasonic motor stator with the finite volume method," Ultrasonics, vol. 77, pp. 69-78, 2017.

[5] I. A. Renteria-Marquez, A. Renteria-Marquez, and B. T. L. Tseng, "A novel contact model of piezoelectric traveling wave rotary ultrasonic motors with the finite volume method," Ultrasonics, vol. 90, pp. 5-17, 2018.

[6] T. Maeno and D. B. Bogy, "FE analysis and lda measurement of the dynamic rotor/stator contact in a ring-type ultrasonic motor," Journal of Tribology, vol. 115, no. 4, pp. 625-631, 1993.

[7] D. Sun, J. Liu, and X. Ai, "Modeling and performance evaluation of traveling-wave piezoelectric ultrasonic motors with analytical method," Sensors and Actuators A: Physical, vol. 100, no. 1, pp. 84-93, 2002.

[8] H. Storck and J. Wallaschek, “The effect of tangential elasticity of the contact layer between stator and rotor in travelling wave ultrasonic motors," International Journal of Non-Linear Mechanics, vol. 38, no. 2, pp. 143-159, 2003.

[9] J. Qu, F. Sun, and C. Zhao, "Performance evaluation of traveling wave ultrasonic motor based on a model with visco-elastic friction layer on stator," Ultrasonics, vol. 45, no. 1-4, pp. 22-31, 2006.

[10] S. Shen, H. P. Lee, S. P. Lim, and C. J. Ong, "Contact mechanics of traveling wave ultrasonic motors," IEEE Transactions on Magnetics, vol. 49, no. 6, pp. 2634-2637, 2013. 
[11] T. Mashimo and K. Terashima, "Dynamic analysis of an ultrasonic motor using point contact model," Sensors and Actuators A: Physical, vol. 233, pp. 15-21, 2015.

[12] J.-S. Ro, S.-Y. Jung, C.-G. Lee, and H.-K. Jung, "Survey of a contact model and characteristic analysis method for a travelling wave ultrasonic motor," International Journal of Applied Electromagnetics and Mechanics, vol. 46, no. 3, pp. 437-453, 2014.

[13] J.-S. Ro, K.-P. Yi, T.-K. Chung, and H.-K. Jung, "Characteristic analysis of an traveling wave ultrasonic motor using a cylindrical dynamic contact model," Journal of Electrical Engineering \& Technology, vol. 8, no. 6, pp. 1415-1423, 2013.

[14] P. L. Moal, E. Joseph, and J.-C. Ferniot, "Mechanical energy transductions in standing wave ultrasonic motors: analytical modelling and experimental investigations," European Journal of Mechanics - A/Solids, vol. 19, no. 5, pp. 849-871, 2000.

[15] J. Twiefel, W. Wurpts, and J. Wallaschek, “Theoretical and experimental treatment of standing wave type motors contact behavior," in Proceedings of the 2009 IEEE International Ultrasonics Symposium, IUS 2009, Rome, Italy, September 2009.

[16] Y. Shi, C. Zhao, and J. Zhang, "Contact analysis and modeling of standing wave linear ultrasonic motor," Journal Wuhan University of Technology, Materials Science Edition, vol. 26, no. 6, pp. 1235-1242, 2011.

[17] Y. Shi, C. Chen, and C. Zhao, "Transient response model of standing wave piezoelectric linear ultrasonic motor," Journal Wuhan University of Technology, Materials Science Edition, vol. 27, no. 6, pp. 1188-1192, 2012.

[18] X. Li, Z. Yao, Q. Lv, and Z. Liu, "Modeling stick-slip-separation dynamics in a bimodal standing wave ultrasonic motor," Journal of Sound and Vibration, vol. 382, pp. 140-157, 2016.

[19] X. Li, Z. Yao, and R. Wu, "Modeling and analysis of stick-slip motion in a linear piezoelectric ultrasonic motor considering ultrasonic oscillation effect," International Journal of Mechanical Sciences, vol. 107, pp. 215-224, 2016.

[20] C. Jiang, X. Dong, J. Zhang, and L. Jin, "The stator dynamics of a radial composite ultrasonic motor," in Proceedings of the 19th International Conference on Electrical Machines and Systems, ICEMS 2016, Chiba, Japan, November 2016.

[21] J. Li, S. Liu, J. Qu, Y. Cui, and Y. Liu, "A contact model of traveling-wave ultrasonic motors considering preload and load torque effects," International Journal of Applied Electromagnetics and Mechanics, vol. 56, no. 2, pp. 151-164, 2018. 


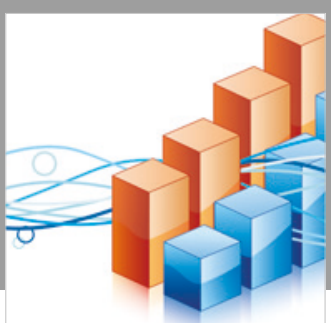

Advances in

Operations Research

\section{-n-m}
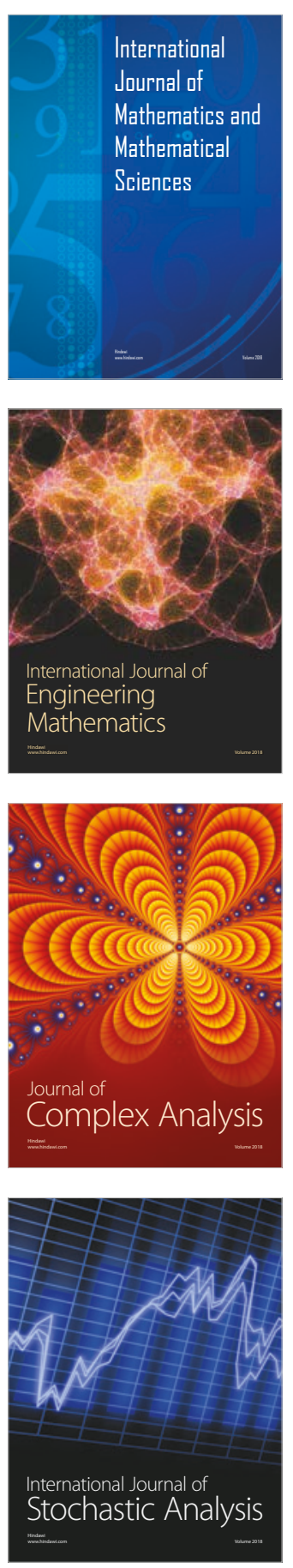
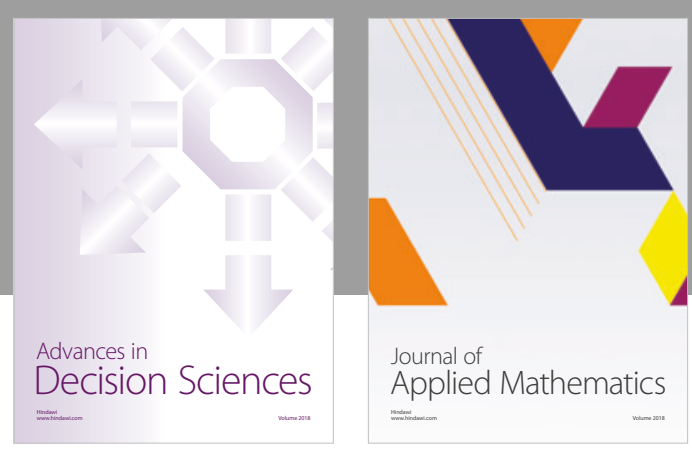

Journal of

Applied Mathematics
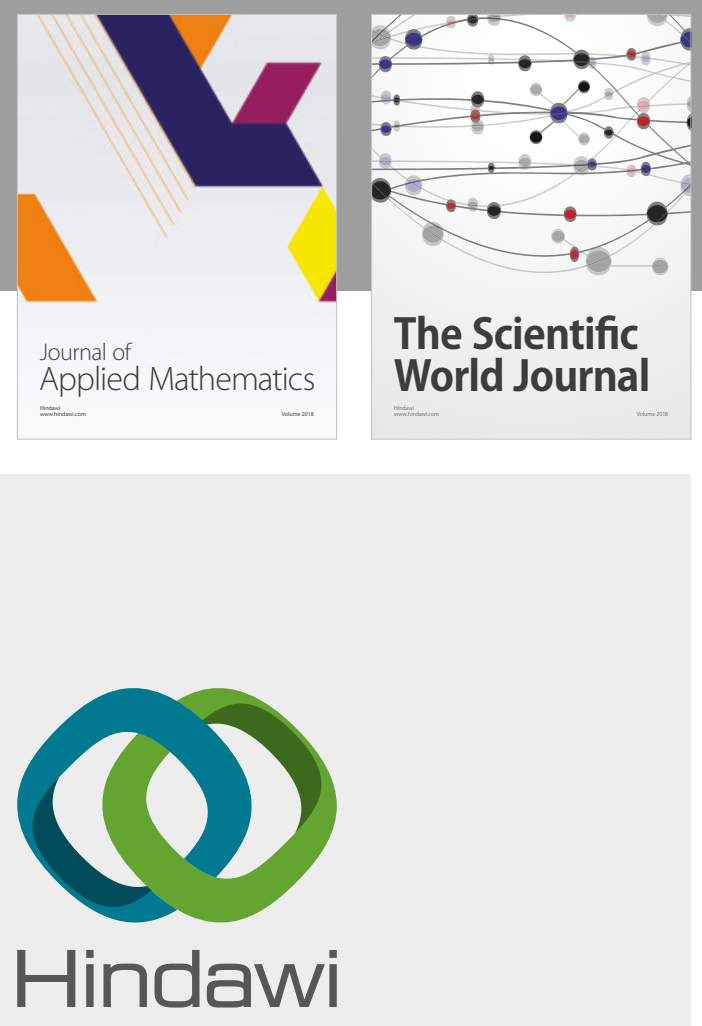

Submit your manuscripts at

www.hindawi.com

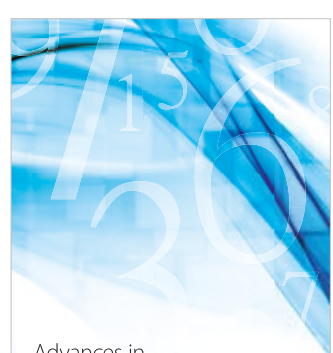

Advances in
Numerical Analysis
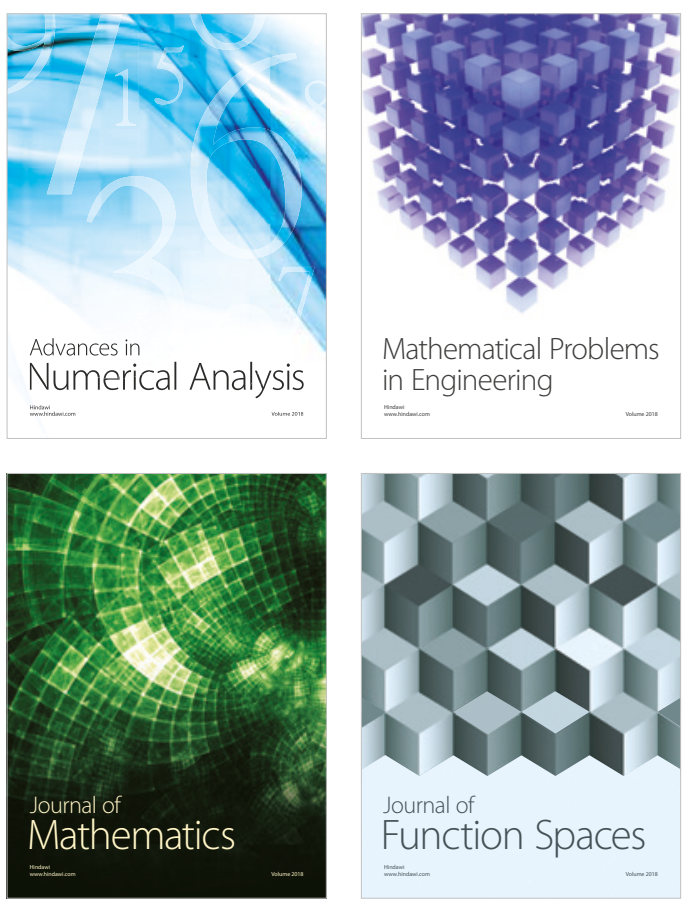

Mathematical Problems in Engineering

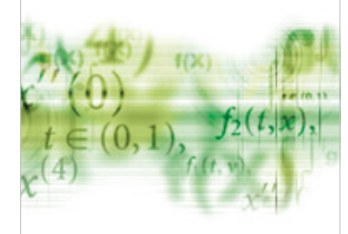

International Journal of

Differential Equations

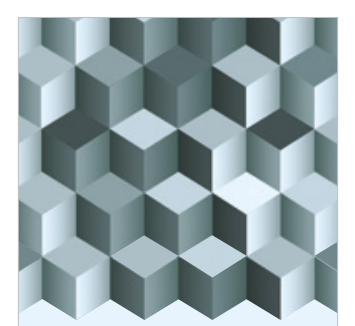

Journal of

Function Spaces

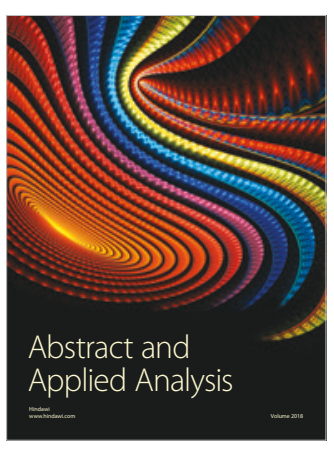

The Scientific

World Journal

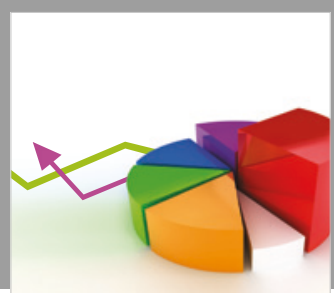

Journal of

Probability and Statistics
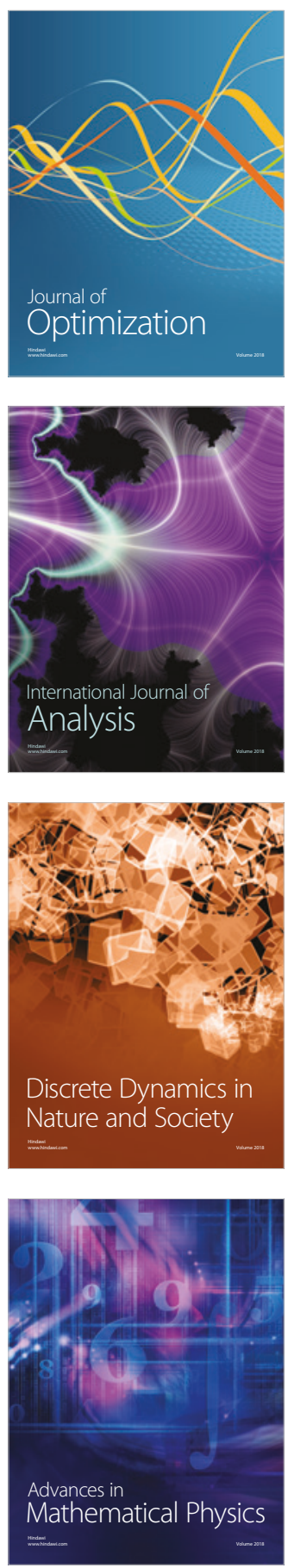